\title{
The Transfer of Affective Knowledge as Anthropological Knowledge
}

\author{
By Matan Shapiro (University College London)
}

Contemporary academic discourse renders knowledge transfer as a reciprocal procedure, which is supposed to generate political engagement, partnership and consent by sharing truthful information. The travel of information in everyday life may, however, also be thought of in light of disengaging dynamics associated with falsifying, concealing, deceiving, disguising and lying. Departing from practices of jealousy, sexual betrayal and gossip in a popular neighborhood in North East Brazil, this article proposes that the transfer of information in the neighborhood necessarily involves strategic considerations about the complex interconnectedness of truth and lie in quotidian practice. In that regard a narrative is constituted by successfully omitting and occluding some facts just as much as it is by revealing others.

\section{Introduction}

This article introduces the concept of 'affective knowledge' - an experience of or expertise in the affective capacities of the human body as they are worked upon and reciprocated in the context of a popular neighborhood I fictionally call Santo-Amaro, which is located in the capital city of Maranhão, North East Brazil. The term 'affective knowledge' includes accepted local forms of bodily proximity and conduct as they materialize in gestures and touch; narratives of sexual conquest or betrayal; gossip and scandal associated with sexual activity and general morality; valued or controversial dressing codes; masculine and feminine courting maneuvers; manipulation and deception associated with the legitimization or concealing of extramarital sexual affairs; and other tactics persons employ to effectively evoke emotional or somatic interchange. Affective knowledge is an analytical tool by which I strive to theorize the political dimension of such carnal and emotional experiences in everyday life in the neighborhood.

Evidently, this article is also an act of anthropological 'knowledge transfer' - the transition of epistemological concerns 'over' affective knowledge to the readers of this journal. As a producer of 'anthropological knowledge' the text thus intends to (a) facilitate a description of 'affective knowledge' and (b) engage in a dialogue with anthropological accounts of sexuality and kinship on the Brazilian socioeconomic margins. The contiguity of these two goals is not, however, self-evident or easily reconcilable, because knowledge A may indeed contradict rather than conflate with knowledge B (cf. Crook 2007 for an interesting analysis of the 'Min enigma' in Melanesia). In order to transfer (analytic) anthropological knowledge about (heuristic) affective knowledge, I would thus need to convince my readers that there is a 
common conceptual basis between these two formulations of knowledge and create a viable link between them (Handelman 2008; Geertz 1974).

It is precisely at this crucial epistemological point of connectivity, however, that much of anthropological knowledge on sexuality and kinship in Brazil fails to create a clear bridge between what the informants do or say and what the anthropologist wishes to say. This is the case partly because anthropologists writing on the Brazilian periphery sometimes employ what their informants do or say only in order to signify a radically differentiated analytical juxtaposition of arguments to that originally implied in the ethnographic context (Holbraad 2008). Such acts produce compelling anthropological theories that often negate the cohesiveness of informants' assumptions about the world (Holbraad 2008; Strathern 1988, 1995).

Whereas the reconstruction of ethnographic events is not necessarily a problem (after all, my informants in the neighborhood do exactly that when they make up imaginative stories about themselves or deliberately conceal some facts about their life history in order to get laid, for example), negating the assumptions my informants have about the world is a problem. Such an act annuls that crucial link between anthropological knowledge and local knowledge; it often creates an unnecessary analytical distinction between hierarchies of truths and knowledge, implying a priori that your play with the ethnographic material is more genuine and 'elaborate' than theirs.

This is not just a semantic or technical problem within anthropological knowledge transfer, but an essential dilemma. As Tony Crook (2007) puts it in his discussion of the relations between the Min 'textual person' and the anthropological knowledge produced about Min cosmology, what matters is the 'relationships within the text not those beyond the text. The relationships... are those between orders of knowledge and between different forms of aesthetic reckoning, which are every bit as social as those between voices in discourse' (Crook 2007: 220). Whereas Crook concentrates on the 'aesthetic' aspects of the problems of relations between different orders of knowledge, I focus on its epistemological aspect, turning on the dual trajectories of 'affective knowledge': on the one hand it is a term stemming from the ethnographic reality it aspires to represent (knowledge A) and on the other hand it is a term which criticizes directly what some anthropologists write about similar ethnographic realities (knowledge B). Can I convey the concept 'affective knowledge' in such a way that remains faithful to ethnographic truth (in its crudest form, namely as 'lived experience' on which informants report) and at the same time finds common ground with anthropological knowledge, which negates the political merit of that truth?

Such a question is more far-reaching than the scope of this article. Here I wish to begin by suggesting that the link between what my informants do/transfer and what I do/transfer as an anthropologist depends on recognizing the performative quality of both these kinds of knowledge in their respective contexts, which necessarily adheres to certain idiosyncratic rules, considerations and conventions. Building on one aspect of affective knowledge - the performative quality that characterizes practices of deception and lies in Santo-Amaro in and around practices of marital infidelity - I argue that anthropological knowledge transfer becomes politically effective (i.e., it may elicit an epistemological transformation) only when it manages to conduct a truthful performance a posteriori, rather than project itself as truthful a priori. 


\section{Affective Knowledge and Truthful Performance in Santo-Amaro}

The aim of 13 months of fieldwork I conducted in Santo-Amaro was to describe how overlapping ethical codes permeating gender practice in popular neighborhoods simultaneously emphasize individual sexual autonomy and the precedence of familial responsibilities/commitments. For example, in Maranhão, as in other peripheral regions of Brazil, prevailing consensual unions and passionate sexual affairs take place in parallel with established matrimonial relations (cf. Linger 1992; Eduardo 1966 [1948]). Contestations over ideal and pragmatic gender roles are frequently imbued in the figure of the corno ('cuckold') and the idiom of chifres ('horns'), which are locally employed as a focus of neighborhood gossip (Fonseca 2003a; cf. Brandes 1980, 1981). This renders gender space amongst the popular classes both conflictual and complementary, hinting at (a) the equally frequent, if less visible, sexual liaisons of women, taking place in parallel to self-declared masculine sexual autonomy (cf. Woortmann 1987) and (b) the active negotiation on the character of intra-familial relations locally carried out by both men and women.

Such overlap becomes possible through, and is organized by, local codes of affective knowledge - the expertise of provoking, distributing and managing affective interchange in socially familiar contexts (such as your neighborhood [bairro], street $[\mathrm{rua}]$ or the nearest public square $[$ praça $]$ ). More specifically, gender interaction within and across structured relations is perceived as a situational encounter heavily dependent on bodily affect and concomitant emotive manifestations that 'capture' persons in a seductive game. In order to be involved in this seductive game, local residents need to (a) master the pragmatic techniques which make up for the game of disclosures in the first place and (b) 'feel', anticipate and mold responses to dynamic affective situations in which they either capture others or are captured by them (cf. Bourdieu 1990 [1977]). The point is that 'relationship' is not seen as singular or 'pure' but utterly plural as it stretches out to the social world of performance rather than focusing on one-to-one interaction.

One aspect of that seductive performance is the quite prosaic assertion that in order to participate effectively in it you must necessarily also engage in strategic considerations about the complex interconnectedness of truth and lies in quotidian practice. To simplify that, if you are a Santo-Amaro young man who wishes to pick up a woman in a bar, you are not expected to tell her who you are or be in any way 'honest' about your intentions, but rather, you are expected to invent by way of lying. The interesting issue is that it is not only your peers who expect that from you but also the occasional girl. ${ }^{1}$ Performing well, rather than being 'truthful', is the main feature characterizing practices of affective knowledge in Santo-Amaro. Ultimately, however, performance should be 'truthful' in order to capture and evoke. Even when you know that you are lying and the girl knows that you are lying, you should be convincingly charming enough with your lies in order not to be perceived as nasty. This is what I mean by the term 'truthful performance' (cf. Schechner 1986).

\footnotetext{
${ }^{1}$ Kinship relationality is crucial here - he or she might have families with some historical friction or animosity, or he or she might also happen to be married. In the latter case, men and women in SantoAmaro tend to hide the fact they are married or magnify it, depending on what they read of the situation. If being married might increase the excitement associated with sexual transgression, it might be introduced into the game.
} 
An actor's moral conduct may thus only become politically effective in the neighborhood by omitting or occulting certain facts while carefully revealing others. As a resident called Gerson once ironically exclaimed - 'truth doesn't stop being truthful once it is omitted'. It follows that in Santo-Amaro it is generally agreed that both men and women cannot fully trust their spouses. Terrifying stories of sexual infidelity circulate in the neighborhood, suggesting that a proper spouse should always keep an eye open and present ciúmes whenever it is required in order to secure marital fidelity. ${ }^{2}$ Such measures are essential since infidelity is viewed as an almost occasional consequence of altered emotional and corporal states of being. As Jackson, a resident of the bairro, explains:

'Let's say a woman goes into the bank to pay a bill. And let's say that all of a sudden (de repente) she meets a man waiting in the queue. This man reads her body language quickly and knows she needs something. He then opens a conversation with her and all of a sudden he writes his telephone number and gives her the note. And let's say that when that woman goes back home she all of a sudden has a fight with her husband about something. She is sad and upset and all of a sudden she resolves calling the number that man from the bank has left in her hands. So all of a sudden several days later she already meets the man for lunch or something of that sort. The man is smart (esperto), and he knows how to talk to her. A week later they meet again and by this time they are already "together" (ficando)'.

These hypotheses about what could happen 'all of a sudden' are shared knowledge in Santo-Amaro and other locations in Maranhão. The immediacy of such interchange and the ways it is seen to capture persons constitute a game, and being involved in it means that one cannot possibly be truthful about what he or she experiences as what they 'are'. In general such inventiveness is seen as the basis for any sexual involvement and even the grounds for long-lasting romantic relationships. A woman called Luisa even told me that namoro (boy/girlfriend relations) do not necessarily require liking the namorado (boyfriend) but being involved with him in a game of mistrust, which also often includes sexual 'betrayal' (sic.). She reckons that love is something that evolves through the relationship and not a predetermined spiritual condition or emotional disposition, and thus it is totally unexpected. Consequently, trust within conjugal relationships is often disregarded as naiveté at best, if not utterly foolish. In that respect, occultation and cover-up stories are often shared between peers and colleagues, whether men or women, as they engender particular allies (who share a secret) across kinship and amity arrangements while separating between (or at least introducing conspiratorial elements into) vernacular structured linkages. This forms a dangerous game of disclosures that may require pragmatic collaboration.

And yet, in Santo-Amaro the sudden revelation of explicit transgression from the moral order is actually more dangerous than transgression itself. This is so since, when scandals do erupt thanks to 'loose tongues', open conflict may ensue (cf.

\footnotetext{
${ }^{2}$ Ciúmes translates as jealousy or envy. I prefer using the original Portuguese in order to maintain its double-edged meaning, indicating simultaneously the possessing of and caring for a person.
} 
Gluckman 1963). Most people I know in Santo-Amaro would do everything to avoid open conflict, which is potentially risky not only to structured kin relations but also to the whole fabric of complex living arrangements within and across extended-family households. Take the following event, as recorded in my field-notes. It deals with the potential sexual infidelity of Paulo, which cuts across two households and highly jeopardizes the interconnectedness of two families that are linked through kin, ritual and amity ties:

\begin{abstract}
'At some stage, around 10.30 at night, the beers were finished. I wanted to go home but Ana convinced us all to sit at Dona Joana's street-bar for last beers. We sat at a table - me, Ana, Neia, Eva, Maria, Rômolo and Fabio. I was talking to Ana about something when she suddenly stopped me and turned to Neia, asking what she is talking about with Eva. Eva responded that she doesn't understand too, since from Neia's talk it appears that Paulo (Eva's husband and Ana's brother), is "eating" (comendo) Marluce; a nonkin woman who lives at Paulo's family's household and works as the care taker of the child of one of Paulo's sisters. ${ }^{3}$ Ana was stunned for a minute since she and her sister Pamella had been stalking Paulo for some time now, suspecting he is indeed "eating" Marluce. She shared her suspicions with me but said that for now they are not going to tell anybody without definitive proof. She then asked Neia who told that to her. Neia replied it is not important but the fact is that she knows about it for more than a month and can't keep her mouth shut anymore. She said that Ana knew about this all along and never said anything to Eva since she is Paulo's sister. Eva was embarrassed but kept smiling, saying she doesn't want to respond now and that anyways Paulo has a right to go with whoever he wants since after the last time he left the house - some 3 years ago - they clarified very well that she is not obligated to be loyal to him too. She referred to him as "the father of my child", and not as a husband. Neia said that she can't stand the face of Marluce and that she can't believe that Marluce still "shows her face" at Eva's household (where Neia, who is married to Eva's brother, also lives with her children). Nelson, another friend who was hanging around the praça and heard the whole argument, entered the house to tell Paulo what had happened and Paulo left the house very angry. He accused Neia of slandering him. She exclaimed again that everybody in the household knew about this, and that they didn't say anything to Eva in order to protect him. Then the fight began'.
\end{abstract}

To cut a long story short, Paulo consistently denied he had ever had anything with Marluce while Neia kept accusing Paulo's brothers and sisters - including Ana who is both Eva's best friend and Paulo's sister - of covering up for him. Neia's attitude exploded the situation, bringing about an open conflict, maybe since she was also trying to create a stronger pact with Eva at the expense of Paulo's sisters. Since

\footnotetext{
3 'Eating' is a common term used in Brazil to indicate sexual transactions. In that respect men can eat women and women can eat men; there is no upright popular clarity as for the classic active-passive debate. See also Parker 1991.
} 
Paulo was dividing his time between the two households - that of his wife's extended family household and his siblings' household - both these versions could have been 'true'. Occulting, covering, concealing and then (maybe) lying were all essential for sustaining Paulo's alleged sexual betrayal, although on the surface he kept claiming complete rectitude while hiding any incriminating details and even accusing others of defaming him. The big fight echoed for some time but eventually had no meaningful consequences. Paulo resolved to move in permanently with his wife Eva and their nine-year-old son at her extended family's household, and Marluce resolved to refrain from setting foot in that house for a while due to the general tension such an act would have created. By his continuous, stubborn denial Paulo achieved peace as well as a long-lasting solution to his indecision about whether to move in permanently with Eva or not.

Moreover, Paulo eventually managed to sustain his own reliable social image through his mastery of affective knowledge. This is simply because people in the bairro, including Paulo's wife, actually expect such performance to be operated in the first place as a meaningful, reflexive, social drama (see Turner 1987; Linger 2005; DaMatta 1991). To simplify this, it seems that in the context of contemporary SantoAmaro a chain of inventive deceptions structures both the engagement and disengagement of actors with one another since it functions as a redress that actually manages to justify transgression by negating it. Not admitting transgression from the accepted moral conventions permeating gender practice in the neighborhood is thereby inverted through denial to achieve consistency, which reinforces conformity as well as personal fame and integrity. Affective knowledge is indispensible to any conquest, maintenance or disposal of that integrity.

Within the confines of the debate I have outlined so far, then, it appears that certain procedures of emotional and somatic exchange, which undermine legitimate hierarchies, may effectively direct bodily action and gain political merit in everyday life in Santo-Amaro. One of the most crucial skills needed to enact that intimate affectivity simultaneously within and outside the family is associated with a successful concealing of any moral conduct that may attract negative sanction. In that regard, truthful performance of affective knowledge in Santo-Amaro makes it more important to continuously sustain a lie than admitting transgression, which paradoxically makes it possible to stay truthful even while deceiving or 'betraying'.

\section{Anthropological Knowledge on the Brazilian Periphery}

As I hinted at the beginning of this article, much contemporary anthropological knowledge on the Brazilian periphery paints a different picture. Contemporary studies on sexuality and gender in Brazil tend to portray hegemonic power structures in Brazilian society at large as (re)producing macro-level class differences and microlevel domestic hierarchies. With the growing influence of the Brazilian feminist movement in the 1980s, scholars have shifted the focus of gender analysis from miscegenation (Freyre 1963) to the contested and 'strained' nature of contemporary gender relations amongst the Brazilian popular classes (cf. D'avila 2003, Rago 2006). Such critiques build on the assumption that socioeconomic stratification in contemporary Brazil compels the disintegration of 'the patriarchal family' (e.g. Lovell 1999, Stolcke 1991, Caulfield 2000; cf. Linger 2005) side by side with the 'modernization' of patriarchal values (Besse 1996). In this framework, the 
contestation of kinship hierarchies and sexual practice in popular Brazilian neighborhoods becomes either an intrinsic effect of latter-day patterns of social marginality or a deployment of 'the weapons of the weak' (cf. Gregg 2003, Goldstein 2003). Consequently, in contemporary anthropological knowledge about the Brazilian socioeconomic periphery, sexuality and reproduction become mutually exclusive, whereas the morals and pragmatics associated in Brazil with mundane affective encounters are portrayed as pertinent to an ideational world of erotic fantasy.

I propose here two short examples for such acts of anthropological knowledge transfer. Both authors cited seem to hold that (1) prior knowledge about socioeconomic superstructures in Brazil serves as a valid (or truthful) explanation of certain mundane practices in peripheral contexts; and (2) the transfer of such knowledge as anthropological knowledge about the Brazilian periphery should be the focus of analysis by way of negating or occluding local narratives and practices collected from informants. The first is Nancy Scheper-Hughes' (1992) oft-quoted work on violence and maternity in a shantytown in North East Brazil. Arguing against a universalizing middle-class notion of mother-love as 'natural' instinct that necessarily manifests itself in nurturing, Scheper-Hughes claims that women who starved their infants to death in 1980s North East Brazil actually enacted a local manifestation of mother-love, an emotional detachment that responded to continuous socioeconomic impoverishment. Her memorable, disturbing description of mothers' indifference to their angel-babies' attributed 'death wish' thus builds on the assumption that mother-love is culturally constructed and politically sanctioned (Scheper-Hughes 1992: 276, original italics):

'...The apparent indifference of alto women toward the lives and deaths of some of their infants is continuous with, and a pale reflection of, the official bureaucratic indifference of local agents of church and state to the problem of child mortality in North-East Brazil today. The social production of official indifference is similar to what Bourdieu (1977: 172-183) meant by méconnaissance, or "misrecognition", the largely unconscious rejection of the "unthinkable" and "unnamable"... What cannot be recognized in this instance are the social determinants of the overproduction of Nordestino angel-babies'.

Whereas Scheper-Hughes indeed writes a very convincing ethnography about the futility, corruption and overall inefficiency of socioeconomic and bureaucratic mechanisms in 1980s North-East Brazil, she also resorts to negating her informants, who insist that the babies who were starved to death were actually angels who thus did not require food. The knowledge that is transferred to readers therefore fails to create a clear link between heuristic notions of person and relatedness (knowledge A) and analytic concerns about the malfunctioning of authorities (knowledge B). Such knowledge transfer is problematic, as I have tried to show, since it goes against its own epistemological foundations; if they say the angel-babies do not require food and you say this is méconnaissance, I suggest you show what the link is between being an angel and méconnaissance, or alternatively how being an angel may transform our own understanding of what méconnaissance is. 
A second example relates directly to notions of truthfulness. In her study on domestic violence in Salvador, Sarah Hautzinger (2007) explicitly disagrees with her informants about the definition of sexual relations outside marriage. Whereas Hautzinger refers to such practices as 'adultery', her informant Dona Alegrina insists that a married man who maintains long-term relations with another woman is not adulterous. Dona Alegrina defies Hautzinger when she exclaims:

'No, there's no such thing as a difficult situation. There's such thing as each person minding his own business... Do you know why?... It has to do with love. There's no such thing as love outside of the truth. Love is a very free thing... It's a spontaneous, free thing. And it is a thing with which condemnation does not exist' (Hautzinger 2007: 78).

And yet, Hautzinger condemns love. She reports that the attribution of independent agency to practices of love and passion in a Salvador favela does in the end inspire 'adultery', although her informants continue to proclaim it is actually a libertarian practice engaged in by both men and women who follow their 'internal truth'. Hautzinger's take on that assertion is:

'Dona Alegrina's notion of her own triumph hinged on her acceptance that human desire and impulse, as well as love's own free force, could not be controlled by abstract moral imperatives, such as those condemning adultery... Mintz's (1974) observations of related forms of distinct individualism among Afro-Caribbean run a similar course, suggesting that these forms derive from shared historical processes, most notably involving rapid cultural loss through enslavement and the forcible, accelerated, and improvised recreation of culture' (Hautzinger 2007: 79-80, italics mine).

But what if Dona Alegrina did not 'lose' her culture? What if she actually practices an alternative conjugal ethic, which is just as elaborately 'abstract' as that advanced by Hautzinger? In fact, Dona Alegrina seems to protect a morality that is focused on passionate or affectionate inclusion instead of exclusively rejecting middle-class moral imperatives. If Dona Alegrina's notions of truth and love go beyond the ethnographer's assumptions and not against them, it suggests a heuristic demarcation of gender relations that is not compatible with a modern/colonial emotional regime based on trust (Reddy 1997: 327-8; see also Mignolo 2003). Here, as with the ethnographic examples from Maranhão, the affective capacities of the human body actively facilitate the enhancement of intimacy or contestation respectively and inspire the transfer of affective knowledge: the reaffirmation of emotional and carnal interconnectedness by way of which persons negotiate their disposition within ever more flexible networks of kin relations (cf. Gilbert 2007).

Hautzinger's analysis, then, a priori assumes that the dynamics of political power in Brazilian society at large work themselves out in pre-determined ways to secure the dominance of men over women within both private and public domains. Anthropological knowledge that is thus produced correlates the asymmetrical gender system with kinship hierarchies in Brazil only insofar as it testifies to ideological 
rupture - historically constructed through the slavery system in the plantations, modernized and sustained by contemporary 'social inequalities' and economic stratification (Besse 1996; Goldstein 2003) - which presumably segregates sex and desire from the 'real world' of procreation and socioeconomic status (cf. McCallum 1998, and Parker 1991 on 'sexual ideology').

The main problem with such analyses is that they directly contradict much of the existing ethnographic data, which suggests that contemporary Brazilians from the popular classes view some components of emotional, carnal and otherwise affective experiences as the producers of sociopolitical power relations rather than merely being their passive side-effects. As I have demonstrated above, sexual practice, the enactment of local emotional styles (see Reddy 2001), and particularly the masterful, truthful performance of anecdotal deception become pragmatically crucial for the constant bending and reshaping of everyday inequalities. Anthropologists writing on sexuality and gender on the Brazilian periphery therefore tend to ignore the importance of such vernacular manifestations, which I have tentatively grouped under the scheme of 'affective knowledge'.

\section{Conclusion}

When we assume a priori, as Crook (2007) argues, that behind every local (or 'native') act of speech or practice hides a higher, maybe firmer 'truth' yet to be revealed, we miss the somewhat banal fact that people almost always and almost everywhere find indirect ways to negotiate conformity and formal morality $a$ posteriori. The ethnography of affective knowledge in Santo-Amaro - as it is ascribed through practices of deception/manipulation associated with conjugal infidelity - thus facilitates an argument that goes beyond much of the formulation of anthropological knowledge about Brazilian gender relations (see Green 1999 for a similar debate). If there is nothing 'behind' what the informants say or do, analytic concepts are in themselves performances that function within certain boundaries or rules of the game. Rather than being conceived of as truthful revelation of some grim reality (which allegedly exists a priori to the ethnographic experience) analytic arguments should be conceived of as truthful performances that represent ethnographic reality a posteriori.

I have used the term affective knowledge to create a bridge (a posteriori) between what my informants do when they prioritize the affective game over ideational representations of truthful intentions in everyday life and what I do as an anthropologist interested in the possible connections between gender contestations and kinship relations. In this case, I have tried to show that a bridge may be illustrated at least on the basis of one aspect of affective knowledge - that of truthful performance - which creates a link between heuristic (knowledge A) and analytic (knowledge B) descriptions. For that matter, affective knowledge serves here as a particular truthful performance within anthropological discourse that (1) captures local (ethnographic) practices as both the product and producer of viable epistemologies that have little to do with anthropological theory and simultaneously (2) produces a viable theoretical argument that manages to engage with current theoretical debates in Brazilianist anthropology. Here my argument relates directly, again, to Bourdieu's 'practical sense', which 'gives the game an objective sense because the sense of the probable outcome is given by practical mastery of the specific regulations that constitute the economy of a field is the basis of "sensible" 
practices, linked intelligibly to the conditions of their enactment... and therefore immediately filled with sense and rationality for every individual who has the feel for the game' (Bourdieu 1990: 66).

Affective knowledge is therefore also anthropological knowledge in its own right, $a$ posteriori presented to and juxtaposed with ethnographic experience. It counts as 'anthropological knowledge' since it demonstrates how within an ethnographic context social integrity is refashioned over and over again in situational contestations across existing hierarchies, and it juxtaposes it with anthropological accounts of gender inequality in Brazil that suggest exactly the opposite; that is, that integrity is mainly shaped by and is subjected to wider socioeconomic, cultural or political trends. With the term affective knowledge I hope I have managed, although not inevitably, to write anthropology that does not a priori negate the basic assumptions of my informants about the world.

The main conclusion, which stems from this exercise, then, is that by showing the performative quality of deception in Santo-Amaro I cannot possibly transfer any 'anthropological' knowledge 'against' Santo-Amaro liars, but I can at best argue about the untruthfulness of some anthropologists. Only by locating the debate within the realm (or 'field') of the analyst will I be able to truthfully transfer to him/her the 'knowledge' I refined in the field. In this case 'anthropological knowledge' is not exclusively confined to the neologism of 'affective knowledge'; it also includes the assertion that, while empirical contextualization of socioeconomic hierarchies in peripheral Brazil is still relevant to anthropological theory and ethnographic practice, it is nonetheless dismissive of grassroots knowledge(s) about sexuality and about the body, including its affective capacities. I contend that such dismissal often overrides the ways persons entail local knowledge as they negotiate personal positions within kin/family networks. Diluting these negotiations through the prism of 'inequality' obscures vernacular gendered phenomena, stripping them of their vitalizing (or toxic) efficacy.

\section{About the author}

Matan Shapiro is a PhD student at University College London (UCL). His field site is located in the state of Maranhão (North East Brazil). He works on affect and local kinship structures.

\section{Bibliography}

Besse, K. S. (1996), Restructuring Patriarchy: The Modernization of Gender Inequality in Brazil, 1914-1940, Chapel Hill and London: University of North Carolina Press.

Bourdieu, P. (1990 [1977]), The Logic of Practice, Stanford: Stanford University Press.

Brandes, S. (1980), Metaphors of Masculinity: Sex and Status in Andalusian Folklore, Philadelphia: University of Pennsylvania Press. 
---- (1981), 'Like Wounded Stags: Male Sexual Ideology in an Andalusian Town', in S. B. Ortner and H. Whitehead (eds), Sexual Meaning: The Cultural Construction of Gender and Sexuality, New York, New Rochelle, Melbourne and Sydney: Cambridge University Press.

Caulfield, S. (2000), In Defense of Honor: Sexual Morality, Modernity, and Nation in Early-Twentieth-Century Brazil, Durham and London: Duke University Press.

Crook, T. (2007), Anthropological Knowledge, Secrecy and Bolivip, Papua New Guinea: Exchanging Skin, Oxford: Oxford University Press.

DaMatta, R. (1991), Carnivals, Rogues, and Heroes: An Interpretation of the Brazilian Dilemma, Notre Dame: University of Notre Dame Press.

Dávila, J. (2003), 'Introduction', in Diploma of Whiteness: Race and Social Policy in Brazil, 1917-1945, Durham, NC: Duke University Press.

Eduardo, da Costa, O. (1966 [1948]). The Negro in Northeast Brazil: A Study in Acculturation. Seattle and London: University of Washington Press.

Fonseca, C. (2003), 'Philanderers, Cuckolds, and Wily Women: Reexamining Gender Relations in a Brazilian Working-Class Neighborhood', in C. M. Gutmann (ed.) Changing Men and Masculinities in Latin America, Durham: Duke University Press.

Freyre, G. (1963), The Mansions and the Shanties (Sobrados e mucambos): The Making of Modern Brazil, New York: Knopf.

Geertz, C. (1974), "From the Native's Point of View": On the Nature of Anthropological Understanding', Bulletin of the American Academy of Arts and Sciences, 28(1): 26-45.

Gilbert, K. W. (2007), 'Slowness: Notes towards an Economy of Différancial Rates of Being', in P. Clough and J. Halley (eds), The Affective Turn: Theorizing the Social, Durham and London: Duke University Press.

Gluckman, M. (1963), 'Gossip and Scandal', Current Anthropology, 4(3): 307-316.

Goldstein, M. D. (2003), Laughter Out of Place: Race, Class, Violence and Sexuality in a Rio Shantytown, Berkeley, Los Angeles and London: University of California Press.

Green, J. N. (1999), Beyond Carnival: Male Homosexuality in Twentieth-Century Brazil, Chicago: University of Chicago Press.

Gregg, L. J. (2003), Virtually Virgins: Sexual Strategies and Cervical Cancer in Recife, Brazil, Stanford: Stanford University Press.

Handelman, D. (2008), 'Afterward: Returning to Cosmology - Thoughts on the Positioning of Belief', Social Analysis, 52(1): 188-95. 
Hautzinger, J. S. (2007), Violence in the City of Women: Police and Batterers in Bahia, Brazil, Berkeley, Los Angeles and London: University of California Press.

Holbraad, M. (2008), 'Definitive Evidence, From Cuban Gods', Journal of the Royal Anthropological Institute (N.S.), 14(S1): S93-S109.

Linger, T. D. (1992), Dangerous Encounters: Meaning of Violence in a Brazilian City, Stanford: Stanford University Press.

---- (2005), 'The Hegemony of Discontent', in T. D. Linger, Anthropology Through a Double Lens: Public and Personal Worlds in Human Theory, Philadelphia: University of Pennsylvania Press.

Lovell, A. P. (1999), 'Women and Racial Inequality at Work in Brazil', in M. Hanchard (ed.), Racial Politics in Contemporary Brazil, Durham and London: Duke University Press.

McCallum, C. (1998), 'Restraining Women: Gender, Sexuality and Modernity in Salvador da Bahia’, Bulletin of Latin American Research, 18(3): 275-93.

Mignolo, W. D. (2003), Histórias locais / projetos globais: Colonialidade, saberes subalternos, e pensamento liminar, Belo Horizonte: Editora UFMG.

Parker, G. R. (1991), Bodies, Pleasures, and Passions: Sexual Culture in Contemporary Brazil, Boston: Beacon Press.

Rago, M. (2006), 'Trabalho Feminino e Sexualidade', in Del Priore, M. and C. Bassanezi (eds), Historia das Mulheres no Brasil, São Paulo: Contexto.

Reddy, M. W. (1997), 'Against Constructionism: The Historical Ethnography of Emotions', Current Anthropology, 38(3): 327-51.

---- (2001), The Navigation of Feeling: A Framework For the History of Emotions, Cambridge: Cambridge University Press.

Schechner, R. (1986), 'Magnitudes of Performance', in V. Turner and E. Bruner (eds), The Anthropology of Experience, Urbana and Chicago: University of Illinois Press.

Scheper-Hughes, N. (1992), Death without Weeping: The Violence of Everyday Life in Brazil, Berkeley, Los Angeles and New York: University of California Press.

Stolcke, V. (1991), 'The Exploitation of Family Morality: Labour Systems and Family Structure on São Paolo Coffee Plantations, 1850-1979', in E. Jelin (ed.), Family, Household and Gender Relations in Latin America. London: Kegan Paul International; Paris: UNESCO.

Strathern, M., (1988), The Gender of the Gift, Berkeley, Los Angeles and London: University of California Press. 
Strathern, M. (1995), 'The Nice Thing about Culture is that Everyone Has It', in Strathern M. (ed.) Shifting Contexts: Transformations in Anthropological Knowledge, London and New York: Routledge.

Turner, V. (1987), The Anthropology of Performance, New York: PAJ Books.

Woortmann, K. (1987), A Familia Das Mulheres, Rio de Janeiro: Tempo Brasileiro; Brasília: CNPq. 